\title{
Modelling of Water Pollution Propagation in the Sevastopol Bay
}

\author{
V. N. Belokopytov*, A. I. Kubryakov, S. F. Pryakhina \\ Marine Hydrophysical Institute of RAS, Sevastopol, Russian Federation \\ *v.belokopytov@gmail.com
}

\begin{abstract}
Introduction. Tracking of spread of various contaminations and elaboration of the operational systems to control wrecking discharges are among the important tasks of marine environment monitoring. The processes of transport of the contaminating impurity inflowing from different sewers were modeled based on the diagnostic calculations of water circulation in the Sevastopol Bay.

Data and Methods. The currents field was calculated using the sigma-coordinate version of the Princeton Ocean Model adapted for the regional conditions in the Sevastopol Bay. To calculate the polluting impurity transport, the model of the matter transfer and diffusion was incorporated into the circulation model. The data on the wind speed and direction obtained at the Sevastopol met office, the temperature, salinity and density climatic fields calculated using the information of 2.7 thousands hydrological stations in the Sevastopol Bay, average seasonal variations of the River Chernaya water discharge and the digital bottom relief with spatial resolution $68 \mathrm{~m}$ were used in the model.

Analysis of Results. Numerical experiments on the contaminant propagation from the point of possible discharge in the Gollandiya Bay reveal that dependence of the pollutant movement trajectory (direction) upon the pattern of water circulation is most evident in the Yuzhnaya Bay and less manifested in the central part of the Sevastopol Bay. In case of a wrecking discharge in the River Chernaya mouth, a contaminant spot, regardless of wind conditions, moves to the northwest and reaches the Gollandiya Bay. Further evolution of the polluted water volume is similar to the process developing after a sewage discharge directly within the Gollandiya Bay.

Discussion and Conclusions. The carried out numerical calculations confirm operatioinal capability of the model and its adequate reproduction of the physical processes under study. It permits both to model the circulation seasonal variation and the thermohaline structure of the Sevastopol Bay waters, and to describe more accurately trajectories of the contaminants' spread.
\end{abstract}

Keywords: numerical model, diagnostic calculations, water pollution, Sevastopol Bay.

Acknowledgements: the investigation is carried out within the framework of the RFBR grant, project No 14-45-01028 "Modeling of circulation and processes of transport of pollutants in the Sevastopol Bay", and at support of the RFBR grant, project No 18-05-80028 "Dangerous phenomena".

For citation: Belokopytov, V.N., Kubryakov, A.I. and Pryakhina, S.F., 2019. Modelling of Water Pollution Propagation in the Sevastopol Bay. Physical Oceanography, [e-journal] 26(1), pp. 3-12. doi:10.22449/1573-160X-2019-1-3-12

DOI: $10.22449 / 1573-160 \mathrm{X}-2019-1-3-12$

(C) 2019, V. N. Belokopytov, A. I. Kubryakov, S. F. Pryakhina

(C) 2019, Physical Oceanography

\section{Introduction}

One of the most important tasks of the marine environment monitoring is to control the propagation of different contaminations and to develop the systems for rapid response to emergency discharges. The processes of transport and distribution of contaminants in marine basins are simulated using hydrodynamic models. They are based on nonlinear partial differential equations in partial derivatives that describe the hydrodynamics of a rotating fluid - the evolution of 3D-fields of currents, temperature, salinity, pressure and density. Modern general circulation models also provide the incorporation of various parameters of impurities in the PHYSICAL OCEANOGRAPHY VOL. 26 ISS. 1 (2019) 
marine environment along with hydrodynamic characteristics. 3D equations, representing the dynamics of such parameters, have a form of transport-diffusion equations.

Studies of hydrologic-hydrochemical and hydrodynamic characteristics of the Sevastopol Bay were carried out earlier on the basis of both field observations[1,2] and the results of mathematical modeling [3, 4]. The increased volume of environmental information and modern interdisciplinary mathematical models provided more accurate predictions of the state and dynamics of marine coastal waters [5-9], including for the Black Sea*.

The purpose of this work is to identify possible ways and extent of propagation of polluting impurities coming from various coastal sources in the water area of the Sevastopol Bay in winter and summer seasons on the basis of water circulation diagnostic calculations. These calculations can serve as a basis for creating a system for the region marine environment state monitoring and ensuring its environmental safety.

In this paper the description of the methods and results of the research given in the report on the RFBR grant No. 14-45-01028** is used.

\section{Research method}

Water circulation model and the data. In order to calculate circulation in the Sevastopol Bay a $\sigma$-coordinate model, a version of POM (Princeton Ocean Model) $[10,11]$ adapted to the conditions of the Black Sea coastal regions [12], was applied. POM model is based on the complete system of equations of a free-surface ocean thermo-hydrodynamics in the Boussinesq approximation, hydrostatics and incompressibility of liquid in $\sigma$-coordinates.

For the vertical mixing parameterization the circulation model includes a turbulence model with 2.5 closure level, based on the Rott - Kolmogorov turbulence hypotheses and generalized by G. Mellor and T. Yamada [13] for the case of stratified flux [14]. The calculation of the currents was carried out using diagnostic method, i.e. at a predetermined density field. The use of adaptation methods allows one to obtain consistent fields of currents and densities, but it leads to a strong smoothing of all computational fields, which is undesirable for a basin with complex morphometry [15].

On a rigid side boundary the condition of impermeability and free slip was applied, on the western liquid open boundary - Sommerfeld radiation condition [16] and the one of heat and salt fluxes equality to zero. Digital data set of the bay bottom relief with $68 \mathrm{~m}$ spatial distribution was prepared on the basis of nautical charts and shipboard echosounding surveys. Measurements obtained at Sevastopol weather station were used as a data on wind velocity and direction. Climatic fields of temperature, salinity and density were calculated on the basis of 2.7 thousands hydrologic stations performed in the Sevastopol Bay. Average seasonal variability of the Chernaya River runoff was taken into account in the model.

* Kubryakov, A.I, 2014. [Modeling of Circulation and Mass Transfer Processes in the Black Sea as Applied to the Tasks of Operational Oceanography: doctoral thesis (Phys.-Math.): 04.00.22]. Sevastopol, 399 p. Available at: http://mhi-ras.ru/assets/files/dissertation/Kubryakov_dissertation.pdf [Accessed: 30.11.2018] (in Russian).

** Kubryakov, A.I., 2015. [Modeling of Circulation and Contaminating Impurity Transport Processes in the Sevastopol Bay: Research Report (final)], FSBSI MHI, Sevastopol, 52 p. RFBR grant No. 14-45-01028. Available at: https://esu.citis.ru/ikrbs/1UHVW00KIfdZ15JGu-2cLb00 [Accessed: 10.07.2018] (in Russian). 
Model of contaminating impurity propagation. In order to calculate a transport of contaminating impurity propagation, a transport-diffusion model based on the following equation was incorporated into the circulation model

$$
\frac{\partial C D}{\partial t}+\frac{\partial C u D}{\partial x}+\frac{\partial C v D}{\partial y}+\frac{\partial C \omega}{\partial \sigma}=F_{T}+\frac{\partial}{\partial \sigma}\left(\frac{K_{H}}{D} \frac{\partial C}{\partial \sigma}\right)+\mu C,
$$

where $C$ is a concentration of contaminants; $t$ is time; $u, v$ are the current velocity projections on $x, y$ axes; $\omega$ is a normal to $\sigma$-surface velocity component; $D$ is total depth; $K_{\mathrm{H}}$ is a coefficient of vertical turbulent diffusion; $F_{T} \equiv \frac{\partial}{\partial x}\left(A_{\mathrm{H}} D \frac{\partial C}{\partial x}\right)+\frac{\partial}{\partial y}\left(A_{\mathrm{H}} D \frac{\partial C}{\partial y}\right)$ is a term describing horizontal turbulent diffusion; $A_{\mathrm{H}}$ is a coefficient of horizontal turbulent diffusion; $\mu$ is a coefficient of non-conservativeness, which takes into account the change in the impurity concentration due to chemical and biological transformations and in general case it is a function of coordinates and time.

For a detailed description of the transformation of contaminating impurity that has got into the marine environment, it is necessary, first of all, to know the chemical composition of contamination. Particularly, if this is an oil spill, then evaporation, fractionation, decomposition, surface tension effects and other chemical and biological processes must be taken into account [17]. The task of the work was to estimate the degree of contaminating impurities transport by currents without the impurity transformation description. Therefore, when solving equation (1), the coefficient $\mu$ was assumed to be equal to zero.

On the sea surface and its bottom an absence of impurity fluxes $\frac{d c}{d \sigma}$ was set. In the places where water flows from the computational domain a zero normal impurity flux was taken both on the rigid and liquid side boundaries. In the places where water inflows the domain, $C_{\mathrm{IN}}$ impurity concentration value in the inflowing liquid was set, in our case $C_{\mathrm{IN}}=0$.

Numerical experiments were carried out in the following way. At first, for 7 days of model time only the circulation was calculated at a fixed wind effect. As the calculations showed, during this period the velocity field was established - the control was carried out according to the value of average kinetic energy over the basin volume and average free surface level over the area. At the initial moment of time, the average climate (for January or July) temperature and salinity fields, which remained fixed, were set. Lateral turbulent diffusion coefficient $A_{\mathrm{H}}$ was calculated using the Smagorinsky formula [18]. Then the calculation of contaminating impurity transport itself was carried out, namely: in each of the discharge points in the surface layer the initial conditional concentration $C_{0}=1$ was set vertically. In the rest of the water area $C_{0}=0$, and then along with the model equations the equation (1) was solved for 5 days, i.e. the discharge was assumed to be pulsed one. In the case of a finite-difference approximation of equation (1), a first-order accuracy scheme with counter-flux differences was applied. In order to reduce the scheme viscosity, an iterative Smolarkiewicz scheme [19] with specially determined anti-diffusion rate was used. 


\section{Analysis of the results}

The cases of winter and summer circulation are considered for two possible sources of contamination: the mouth of the Chernaya River and the Gollandiya Bay coastal zone.

The source of discharge is the Gollandiya Bay (winter season). In Fig. 1 the evolution of contaminative impurity at the sea surface is shown. Initially, the spot propagation occurs along the northern shore of the bay with the prevailing surface currents of the north-west direction caused by the eastern wind. In 48 hours after the discharge, the impurity spot reaches the southern shore of the bay in its central part, despite the surface currents which obstruct this. The cause may be horizontal processes and equally the vertical diffusion, as the impurity can get into the surface layer from the underlying layers in which the water circulation differs from the surface one. After 5 days, the boundary of the contaminative impurity spot reaches the Artilleriyskaya Bay.
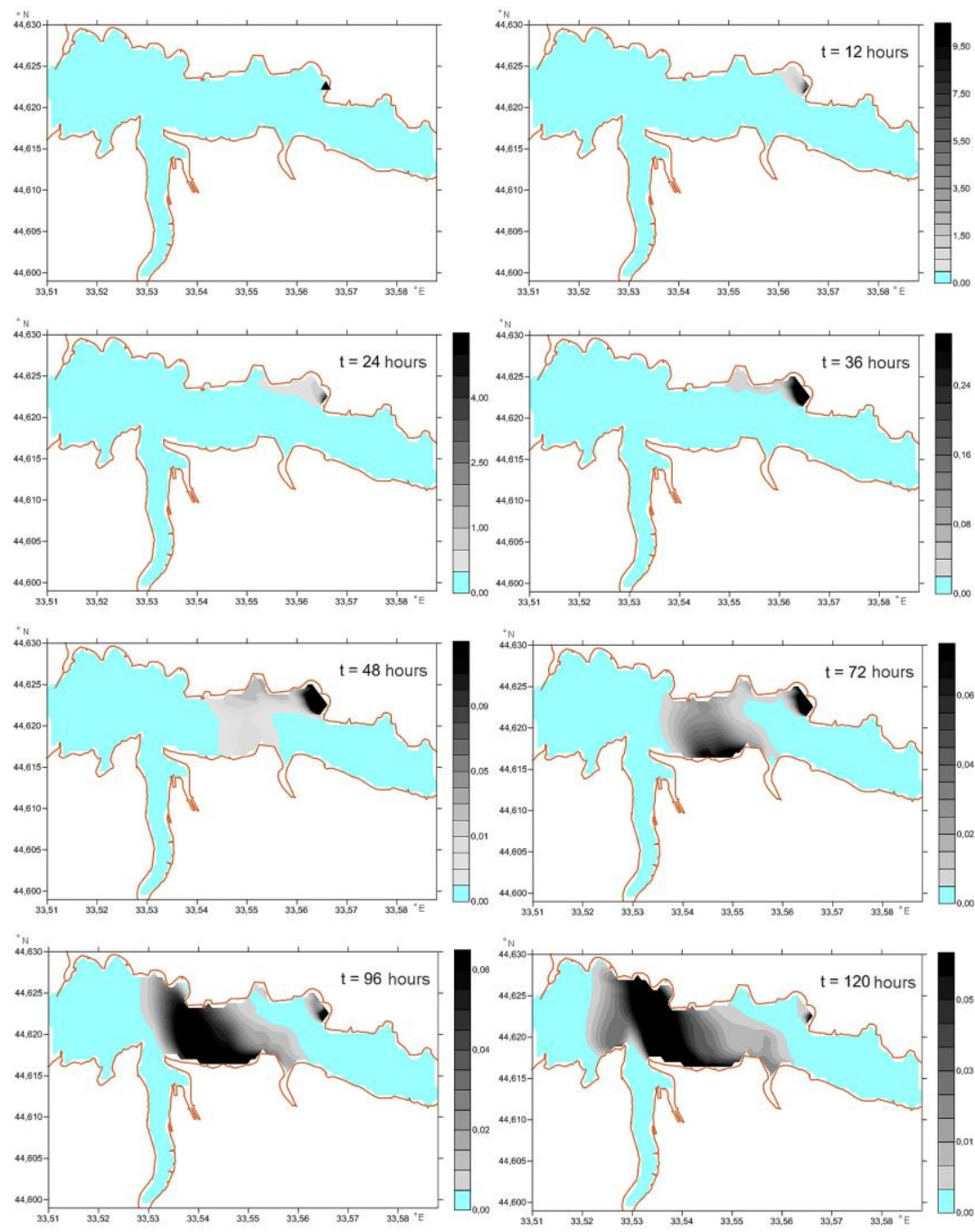

F i g. 1. Location of the impurity spot in the surface layer in winter at different time points $t$ after contamination discharge in the Gollandiya Bay 
In the subsurface layer between the Gollandiya Bay and the Kilen-Bay a cyclonic eddy is formed. It provides the transport of impurities in the south-west direction. This contributes to the contaminating impurity accumulation at the southern coast, where it rises to the surface layer with upward water movements in the upwelling zone and then moves in a western direction. In the bottom layer, processes similar to those occurring in the subsurface layer are observed.

In Fig. 2 the change in impurity concentration after the discharge is shown on two vertical sections after. The impurity penetration into the Yuzhnaya Bay occurs in the bottom layers since the main water flow getting from the Yuzhnaya Bay into the Sevastopol Bay is concentrated in the surface layer. Contamination reaches the surface layer in the upwelling zone at the edge of the Yuzhnaya Bay.

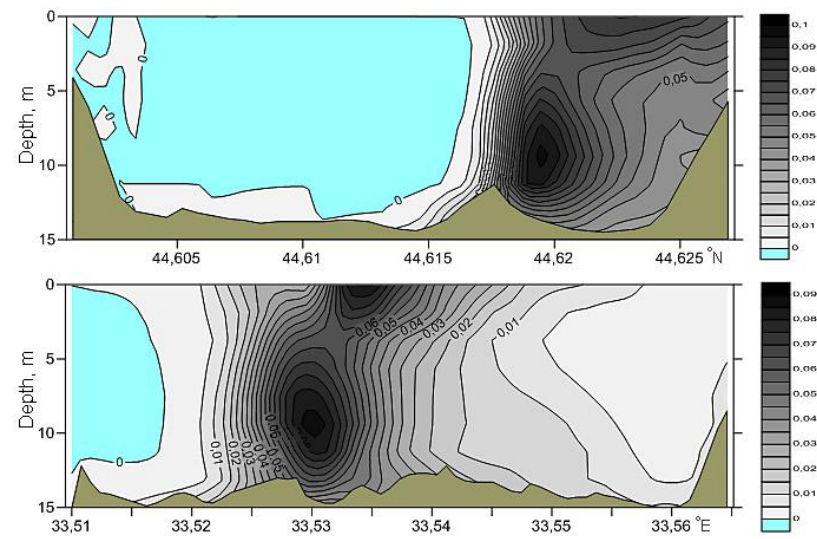

F i g. 2. Distribution of the impurity conditional concentration $(\%)$ in winter on the meridional section $33.533^{\circ} \mathrm{E}(a)$ and the zonal section $44.621^{\circ} \mathrm{N}(b)$ in 5 days after contamination discharge in the Gollandiya Bay

The source of discharge is the Gollandiya Bay (summer season). In contrast to the above-described case of winter circulation induced by the eastern wind, the impurity spot initially propagates to the south, rapidly reaches the southern coast and then moves westward with a general flow. In 3 days the spot boundary reaches the Yuzhnaya Bay and in 4 days - the Artilleriyskaya Bay (Fig. 3).

An impurity brought by the surface currents to the southern coast descends into the subsurface layers in the convergence zone and then it is carried to the central part of the bay providing uniform contamination distribution over the basin. Similar processes occur in the bottom layer. Here, the features of impurity concentration distribution, which are due to the anticyclonic eddy located between the Kilen-Bay and the Yuzhnaya Bay, are more noticeable. 

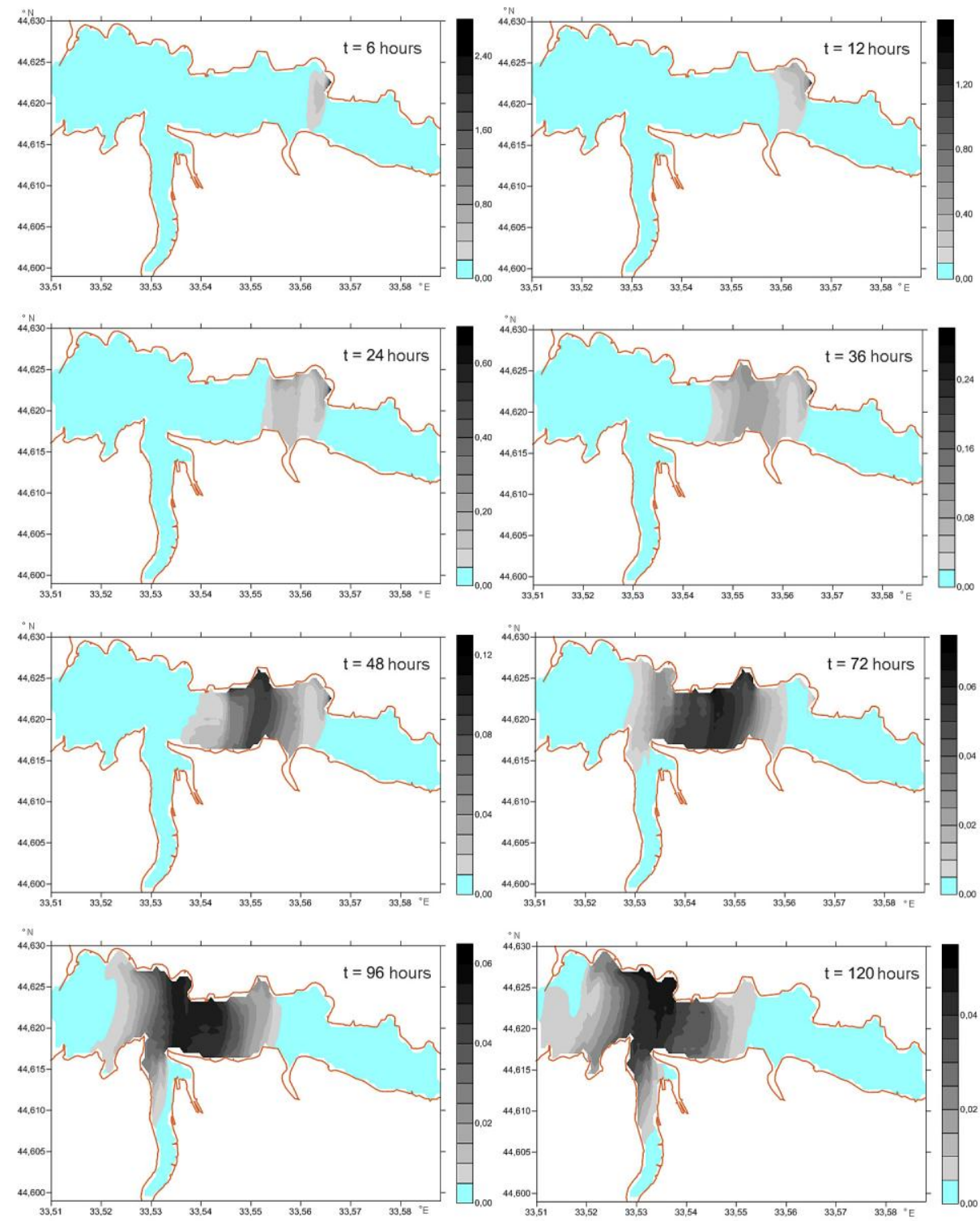

F i g. 3. Location of the impurity spot in the surface layer in summer at different time points $t$ after contamination discharge in the Gollandiya Bay

When considering the impurity vertical distribution (Fig. 4), the greatest differences from the situation obtained in January are manifested in the Yuzhnaya Bay where the contamination spot penetrates the entire water column. 

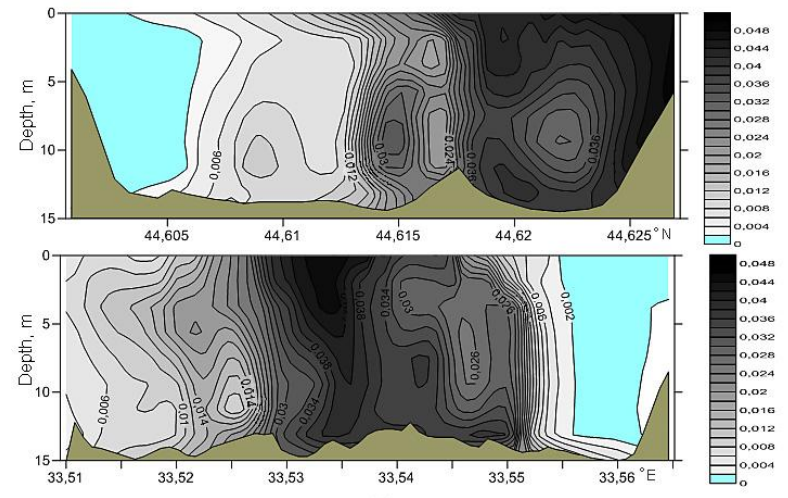

F i g. 4. Distribution of the impurity conditional concentration (\%) in summer on the meridional section $33.533^{\circ} \mathrm{E}(a)$ and the zonal section $44.621^{\circ} \mathrm{N}(b)$ in 5 days after contamination discharge in the Gollandiya Bay

The source of discharge is the Chernaya River estuary (winter season). The structure of currents in the marginal eastern part of the Sevastopol Bay in January is such that the water flow after coming out of narrowness near Inkerman deviates in a northwestert direction towards the Gollandiya Bay.
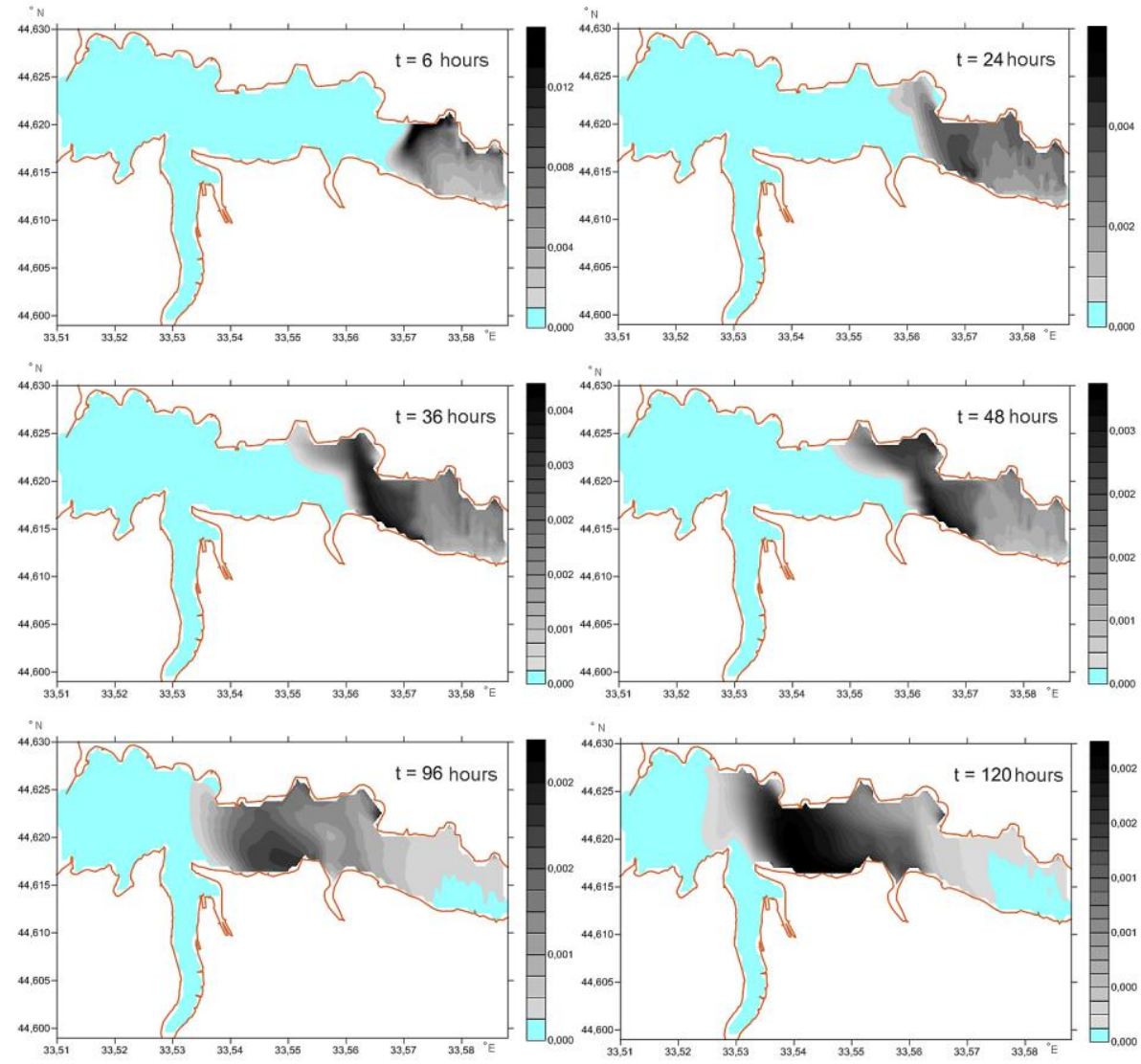

F i g. 5. Location of the impurity spot in the surface layer in winter at different time points $t$ after contamination discharge in the Chernaya River estuary 
The impurity spot passes the distance from the Chernaya River estuary to the Gollandiya Bay in 1 day and rather uniformly fills the Sevastopol Bay eastern part with an increase in contamination concentration from the northern to the southern coasts (Fig. 5, 6). After the impurity reaches the Gollandiya Bay, its further propagation generally corresponds to the above-described case of instantaneous discharge of contaminants directly in the bay itself.
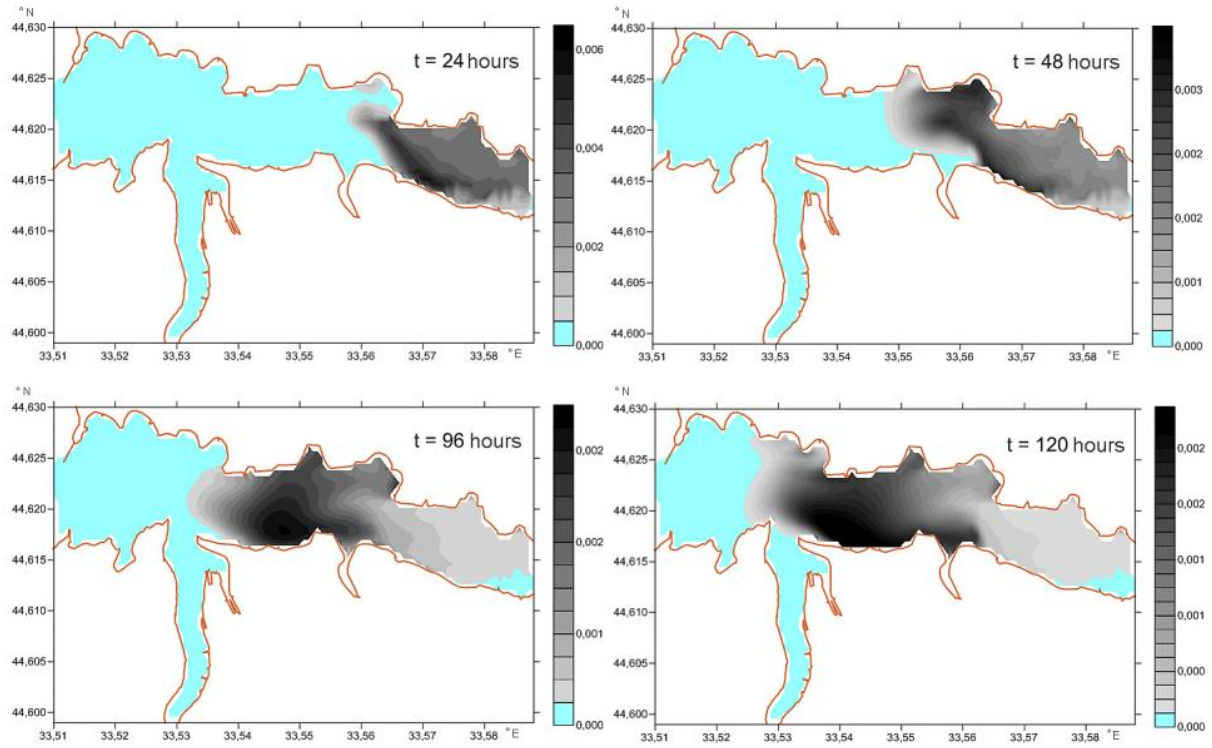

F i g. 6. Location of the impurity spot in the bottom layer in winter at different time points $t$ after contamination discharge in the Chernaya River estuary

The source of discharge is the Chernaya River estuary (summer season). In July, despite the differences in the direction of surface currents compared to January, the integral water transport in the eastern part of the Sevastopol Bay remains the same: the flow deviates in the north-western direction towards the Gollandiya Bay. Therefore, the evolution of the impurity spot corresponds to the situation obtained for January: the contaminated waters pass the distance from the Chernaya River estuary to the Gollandiya Bay in 1 day, uniformly fill the water area of the eastern part of the bay and further propagate as in the case of the contamination discharge in the Gollandiya Bay in July.

\section{Conclusion}

The calculations obtained as a result of numerical experiments on the contaminating impurity propagation from the place of possible discharge in the Chernaya River estuary showed that regardless of wind conditions the impurity spot, moving in the north-western direction, reaches the Gollandiya Bay area. Further evolution of contaminated waters, as well as in the cases of direct discharge in the Gollandiya Bay, mainly depends on the type of water circulation in the Yuzhnaya Bay and, to a lesser extent, on the field of currents in the Sevastopol Bay central part. 
The performed numerical experiments showed the efficiency and adequacy of reconstruction of the processes under study in the model, which provides further planning of the prognostic calculations for simulating the seasonal circulation variation and thermohaline structure the Sevastopol Bay waters. This also provides more accurate description of the ways of contamination propagation.

\section{REFERENCES}

1. Repetin, L.N., Gordina, A.D., Pavlova, E.V., Romanov, A.S. and Ovsyany, E.I., 2003. Vliyanie Okeanograficheskikh Faktorov na Ekologicheskoe Sostoyanie Sevastopol'skoy Bukhty (Chernoe More) [Affect of Oceanographic Factors upon the Ecological State of the Sevastopol Bay (the Black Sea)]. Morskoy Gidrofizicheskiy Zhurnal, (2), pp. 66-80 (in Russian).

2. Ivanov, V.A., Ovsyany, E.I., Repetin, L.N., Romanov, A.S. and Ignat'eva, O.G., 2006. Gidrologo-Gidrokhimicheskiy Rezhim Sevastopol'skoy Bukhty i Ego Izmeneniya pod Vozdeystviem Klimaticheskikh i Antropogennykh Faktorov [Hydrologic and Hydrochemical Regime of Sevastopol Bay and Its Changes under the Influence of Climatic and Anthropogenic Factors]. Sevastopol: ECOSI-Gidrofizika, 90 p. Available at: https://www.researchgate.net/publication/37615620_Gidrologo-

gidrohimiceskij_rezim_Sevastopolskoj_buhty_i_ego_izmenenia_pod_vozdejstviem_klimatice skih_i_antropogennyh_faktorov [Accessed: 10 February 2019] (in Russian).

3. Shapiro, N.B. and Yushchenko, S.A., 1999. Simulation of Wind Currents in Sevastopol Bays. Physical Oceanography, [e-journal] 11(1), pp. 47-64. https://doi.org/10.1007/BF02524495

4. Mikhailova, E.N. and Shapiro, N.B., 2005. Simulation of the Circulation and Space Structure of Thermohaline Fields in the Sevastopol Bay with Regard for the Actual External Data (Winter, 1997). Physical Oceanography, [e-journal] 15(2), pp. 118-132. https://doi.org/10.1007/s11110-005-0035-0

5. Belcaid, A., Le Palec, G., Draoui, A. and Bournot, Ph., 2012. Simulation of Pollutants Dispersion in the Bay of Tangier (Morocco). Fluid Dynamics \& Materials Processing, 8(2), pp. 241-256. doi:10.3970/fdmp.2012.008.241

6. Zong, X., Xu, M., Xu, J. and Lv, X., 2018. Improvement of the Ocean Pollutant Transport Model by Using the Surface Spline Interpolation. Tellus A: Dynamic Meteorology and Oceanography, [e-journal] 70(1), pp. 1-13. https://doi.org/10.1080/16000870.2018.1481689

7. Vikas, M. and Dwarakish, G.S., 2015. Coastal Pollution: A Review. Aquatic Procedia, [ejournal] 4, pp. 381-388. https://doi.org/10.1016/j.aqpro.2015.02.051

8. Mishra, P., Panda, U.S., Pradhan, U., Kumar, C.S., Naik, S., Begum, M. and Ishwarya, J., 2015. Coastal Water Quality Monitoring and Modelling off Chennai City. Procedia Engineering, [e-journal] 116, pp. 955-962. https://doi.org/10.1016/j.proeng.2015.08.386

9. Periáñez, R., 2013. Water Circulation, Sediment Transport, and Pollutant Dynamics in Southern Iberia Waters: A review on Numerical Modelling Studies. ISRN Oceanography, 2013(Article ID 424572), 27 p. http://dx.doi.org/10.5402/2013/424572

10. Blumberg, A.F. and Mellor, G.L., 1987. A Description of a Three-Dimensional Coastal Ocean Circulation Model. In: N. S. Heaps, ed., 1987. Three Dimensional Coastal Ocean Models. Washington D.C.: AGU, pp. 1-16. doi:10.1029/CO004p0001

11. Hunter, J.R. OzPOM: A Version of the Princeton Ocean Model. [online] Available at: https://www.johnroberthunter.org/science/ozpom/index.html [Accessed: 10 February 2019].

12. Kubryakov, A.I., Korotaev, G.K., Dorofeev, V.L., Ratner, Y.B., Palazov, A., Valchev, N., Malciu, V., Mateescu, R. and Oguz, T., 2012. Black Sea Coastal Forecasting System. Ocean Science, [e-journal] 8(2), pp. 183-196. https://doi.org/10.5194/os-8-183-2012

13. Mellor, G.L. and Yamada, T., 1982. Development of a Turbulence Closure Model for Geophysical Fluid Problems. Reviews of Geophysics, [e-journal] 20(4), pp. 851-875. https://doi.org/10.1029/RG020i004p00851

14. Grigorjev, A.V., Kubrjakov, V.A., Fedotova, L.D. and Charikov, I.V., 2011. Numerical Water Dynamics Modeling for Russian South Seas within the Framework of Operational Oceanography. SOI Proceedings, Moscow: SOI. Iss. 213, pp. 80-90 (in Russian). 
15. Ivanov, V.A., Kubryakov, A.I., Mikhailova, E.N. and Shapiro, N.B., 1997. Modelling of Circulation in the Gulf of Izmir. Physical Oceanography, [e-journal] 8(1), pp. 47-55. https://doi.org/10.1007/BF02522565

16. Sommerfeld, A., 1949. Partial Differential Equations. Lectures on Theoretical Physics. N.Y.: Academic Press. Vol. 6. 335 p.

17. Konovalov, S.K., Kubryakov, A.I. and Demyshev, S.G., 2004. Parametrization of the Biochemical Processes of Oxidation and Numerical Modeling of the Seasonal Behavior of the Distribution of Oil Hydrocarbons in the Aerobic Zone of the Black Sea. Physical $\begin{array}{llll}\text { Oceanography, } & \text { [e-journal] } & 14(1), & \text { pp. }\end{array}$ https://doi.org/10.1023/B:POCE.0000025368.38540.a7

18. Smagorinsky, J., 1963. General Circulation Experiments with the Primitive Equations: I. The Basic Experiment. Monthly Weather Review, [e-journal] 91(3), pp. 99-164. https://doi.org/10.1175/1520-0493(1963)091<0099:GCEWTP>2.3.CO;2

19. Smolarkiewicz, P.K., 1984. A Fully Multidimensional Positive Definite Advection Transport Algorithm with Small Implicit Diffusion. Journal of Computational Physics, [e-journal] 54(2), pp. 325-362. https://doi.org/10.1016/0021-9991(84)90121-9

About the authors:

Vladimir N. Belokopytov - Head of Oceanography Department, Marine Hydrophysical Institute of RAS (2 Kapitanskaya Str., Sevastopol, 299011, Russian Federation), Dr. Sci (Geogr.), ORCID ID: 0000-0003-4699-9588, Scopus Author ID: 6602381894, v.belokopytov@ gmail.com

Alexander I. Kubryakov - Deputy Director for Science, Marine Hydrophysical Institute of RAS (2 Kapitanskaya Str., Sevastopol, 299011, Russian Federation), Dr. Sci (Phys.-Math.), ORCID ID: 0000-0003-1899-9230, Scopus Author ID: 6602809060, ResearcherID: F-8959-2014, alexander.kubryakov@mhi-ras.ru

Svetlana F. Pryakhina - Leading Engeneer-Researcher, Marine Hydrophysical Institute of RAS (2 Kapitanskaya Str., Sevastopol, 299011, Russian Federation), odop_mhi_nanu@mail.ru

Contribution of the co-authors:

Vladimir N. Belokopytov - preparation of the data for the boundary and initial conditions of the mathematical model, analysis of the modeling results

Alexander I. Kubryakov - mathematical model development and adaptation to the Sevastopol Bay conditions

Svetlana F. Pryakhina - carrying out the numerical experiments, processing of the modeling results

All the authors have read and approved the final manuscript.

The authors declare that they have no conflict of interest. 